\title{
Influência dos parâmetros físico-hídricos do solo na conformação das vertentes na formação Santa Maria (Membro Alemoa) no Bairro Camobi e Distrito de Pains,
} Santa Maria, RS

\author{
Influence of soil physical hidric parameters in the hillslope conformation \\ in Santa Maria Formation (Alemoa Member) In Camobi And In Pains \\ District, Santa Maria, RS
}

\author{
Ronaldo Facco'; Mauro Kumpfer Werlang"
}

\begin{abstract}
RESUMO
As vertentes, juntamente com os interflúvios e os talvegues constituem, os componentes fundamentais das unidades de relevo. A problemática da presente pesquisa está assentada na observação da ocorrência de uma relativa padronização na forma do perfil das vertentes situadas na Formação Santa Maria (Membro Alemoa), na Depressão Periférica Sul-rio-grandense, município de Santa Maria, no bairro Camobi e distrito de Pains. O objetivo da pesquisa é compreender a influência que os parâmetros físico-hídricos do solo (cobertura pedológica) exercem na conformação das vertentes da Formação Santa Maria (Membro Alemoa), na Depressão Periférica Sul-rio-grandense, no município de Santa Maria, região central do estado do Rio Grande do Sul. Para realização da pesquisa, adotou-se o método hipotético-dedutivo, segundo (Lakatos, Marconi, 2001). De acordo com os objetivos do trabalho, adotou-se também como base teórico-metodológica a proposta de Boulet (1978), que trata da análise estrutural da cobertura pedológica. Conclui-se que as propriedades físico-hídricas do solo influenciam na conformação do perfil convexo-côncavo das vertentes pesquisadas.
\end{abstract}

Palavras-chave: Cobertura Pedológica; Propriedades Físico-hídricas; Vertente

\section{ABSTRACT}

The hillslopes, interfluves, thalwegs are part of the fundamental components of the relief units. The issue studied in this research is based in the observation of the occurrence of some relative padronization in the profile shapes of the hillslopes located on Santa Maria Formation (Alemoa Member), in the Peripheral Sul-rio-grandense Depression, Santa Maria city, in Camobi neighborhood and also in Pains district. This research is aimed to comprehend the influence of the physical hidric parameters of the soil (pedological cover) in the hillslopes comformation of Santa Maria Formation (Alemoa Member), in the Peripheral Sul-rio-grandense Depression, in Santa Maria city, in the central area of Rio Grande do Sul state. In order to carry out this survey, the hypothetical-deductive method was adopted, according to (Lakatos, Marconi, 2001). It was also adopted as a theoretical methodological basis, the Boulet (1978) theory, which considers the structural analysis of the pedological cover. It is concluded that the physical hidric properties of the soil influences the conformation of the convex-concave profile of the studied hillslopes.

Keywords: Hillslope, Pedological cover, Physical and hidric properties

Universidade Federal de Santa Maria, RS, Brasil - https://orcid.org/0000-0003-1794-8351- ronaldo-facco@bol.com.br

"Universidade Federal de Santa Maria, RS, Brasil - http://lattes.cnpq.br/1378915947547752 - mkwerlang@smail.ufsm.br 


\section{INTRODUÇÃO}

Para melhor compreender a dinâmica evolutiva das vertentes, destacam-se as características da cobertura pedológica. Nesse sentido, a importância de estudar a influência do solo na conformação das vertentes é interpretada sendo que a evolução do relevo dar-se a partir das transformações (autodesenvolvimento) dos próprios solos, onde os fluxos hídricos desempenham papel fundamental (Boulet, 1988). As vertentes são esculpidas pela ação da dinâmica externa e modificam-se como resposta aos processos morfoclimáticos aos quais estão submetidas. A forma do perfil das vertentes está relacionada ao substrato litológico e à composição da cobertura pedológica, influenciando as propriedades físico-hídricas do solo onde estão assentadas as vertentes em estudo. Em consideração a isso, propõe-se estudálas assentadas sobre Argissolos com o substrato litológico da Formação Santa Maria (Membro Alemoa).

Partindo do pressuposto de que a vertente é um componente fundamental das unidades de relevo, seu estudo se apresenta fundamental para a compreensão do relevo e seus elementos. A problemática da presente pesquisa está assentada na observação da ocorrência de uma relativa padronização na forma do perfil das vertentes situadas na Formação Santa Maria (Membro Alemoa), na Depressão Periférica Sul-rio-grandense, no bairro Camobi e no distrito de Pains do município de Santa Maria. Essa tendência de semelhança na forma do perfil das vertentes tem como característica formas convexas no terço superior e côncavas no terço inferior das vertentes. Pressupõe-se que essa forma do perfil das vertentes está sendo controlada pelos parâmetros físico-hídricos do solo em uma relação de causa e efeito, em que os parâmetros físico-hídricos da cobertura pedológica condicionam a forma do perfil nessas vertentes.

A justificativa para estudar a influência dos parâmetros físico-hídricos da cobertura pedológica na conformação do perfil das vertentes situadas na Formação Santa Maria (Membro Alemoa) está na cobertura pedológica que, como resultado da 
intemperização do substrato litológico num determinado clima e tempo, adquire propriedades herdadas dos processos de formação, e isso influencia a evolução da forma das vertentes. Nesse sentido, consideram-se os pressupostos de que os parâmetros físico-hídricos da cobertura pedológica influenciam a forma do perfil das vertentes, e de que a conformação das vertentes situadas sobre a Formação Santa Maria (Membro Alemoa) é influenciada pelos parâmetros físico-hídricos do solo, sobre os quais essas vertentes estão assentadas.

Sendo assim, o objetivo geral é compreender a influência que os parâmetros físico-hídricos do solo (cobertura pedológica) exercem na conformação das vertentes da Formação Santa Maria (Membro Alemoa), na Depressão Periférica Sul-riograndense, no município de Santa Maria, região central do estado do Rio Grande do Sul.

Já os objetivos específicos são: Identificar a forma do perfil convexo-côncavo como padrão das vertentes da Formação Santa Maria (Membro Alemoa) na região do bairro Camobi e do distrito de Pains; Descrever os horizontes diagnósticos de perfis de solo em topossequências de vertentes identificadas com a forma do perfil convexo-côncavo na Formação Santa Maria (Membro Alemoa), na região do bairro Camobi e do distrito de Pains; Coletar amostras deformadas e indeformadas em cada horizonte diagnóstico dos perfis descritos e determinar, em laboratório, os parâmetros físico-hídricos: distribuição do tamanho de partículas, microporosidade, macroporosidade, porosidade total, diâmetro dos poros em diferentes tensões $(10 \mathrm{~cm}, 30 \mathrm{~cm}$ e $60 \mathrm{~cm})$, densidade aparente, densidade de partículas e condutividade hidráulica saturada e Demostrar a organização dos horizontes diagnósticos e analisar a influência dos parâmetros físico-hídricos do solo na conformação da forma do perfil em vertentes sobre o substrato litológico da Formação Santa Maria (Membro Alemoa), na região do bairro Camobi e do distrito de Pains. 


\section{REFERENCIAL TEÓRICO}

As vertentes, juntamente com os interflúvios e os talvegues, são entendidos como elementos fundamentais que compõem o relevo, no entanto, quando se refere à concepção de paisagem surgem questões de como e de que maneira ela se processa, qual o desenvolvimento das formas de relevo, quais as condições iniciais e até em que fase se processa a evolução. Convergindo nesse raciocínio, torna-se, portanto, evidente a importância do conhecimento relativo à morfogênese das vertentes a partir do controle exercido pela cobertura pedológica.

O conceito de vertente é essencialmente dinâmico, uma vez que procura delimitar um espaço de relações processuais de natureza geomorfológica, incorporando os mais diferentes tipos de variáveis. Observando a importância do estudo geomorfológico da evolução atual das vertentes, demostrou que o entendimento espaço-temporal dos mecanismos morfodinâmicos atuais e passados levam ao cerne do estudo geomorfológico por excelência, ajudando o entendimento e evolução das paisagens geográficas, (Cruz, 1982).

O sistema geomorfológico bem como a forma das vertentes pode ser analisado a partir do estudo do sistema-processo-resposta. Segundo Gregory (1992, p. 226), “o sistema-processo-resposta, resultante da inter-relação entre as formas, os materiais e os processos que configuram seus elementos". Comportando-se assim, como um sistema em que cada entrada de matéria e energia influência na dinâmica do sistema todo.

O fluxo de matéria e energia pelo sistema vertente, faz com que a transferência de água, sedimentos e elementos químicos ocorram por meio dos vários fluxos superficial e subsuperficial, que variam no tempo e no espaço, ao longo do mesmo, podendo resultar em diferenciações e descontinuidades de processos, tanto em termos das formas das vertentes como de diferentes tipos de solos dispostos em cada segmento topográfico. 
Para (Bertalanffy, 1976), a teoria geral dos sistemas tem, por fim, identificar as propriedades, princípios e leis características dos sistemas em geral, independentemente do tipo de cada um, da natureza de seus elementos componentes e das relações ou forças entre eles. Um sistema se define como um complexo de elementos em interação de natureza ordenada (não fortuita). Tratando das características formais das entidades denominadas sistemas, a teoria geral é interdisciplinar, isto é, pode ser usada para fenômenos investigados nos diversos ramos tradicionais da pesquisa científica.

Conforme Bigarella e outros (1965), a análise da morfologia das vertentes consiste em um importante instrumento de reconhecimento da sequência de eventos operantes no desenvolvimento da paisagem, pois é através dos estudos das diversas formas e de seus depósitos correspondentes que se pode concluir quais as condições ambientais que prevalecem durante esta análise e, ainda, sobre os processos atuantes no desenvolvimento da paisagem.

Portanto, considerando a vertente como um subsistema do sistema relevo e da relação causa e efeito existente entre solo e vertente, compreende-se que as características do solo interferem na forma da mesma.

O solo pode ser o principal condicionador da conformação das vertentes, o que só é possível a partir de certa maturidade do solo, no momento em que os processos pedogenéticos são caracterizados e os mesmos influenciam nas propriedades físicohídricas dos horizontes diagnósticos. A consequência desse condicionamento exercido pelo solo na forma das vertentes, é a intensidade do fluxo de água e sedimentos no perfil do solo, contribuindo assim na movimentação dos mesmos, tanto lateralmente quanto horizontalmente, o qual irá influenciar na forma da vertente.

Assim, conforme Toledo e outros (2008, p. 141), é possível concluir que os solos primeiramente se formam e depois passam por processos de mudanças, ou seja, a partir dessas mudanças os horizontes diagnósticos adquirem características que os fazem distinguirem-se no perfil de solo. 
De acordo com Queiroz Neto (2002), para a compreensão das relações entre os solos e as formas de relevo é necessário superar algumas ideias preconcebidas no que diz respeito a haver uma oposição entre os processos de pedogênese (alteração das rochas, formação dos solos) e de morfogênese (erosão e esculturação das formas de relevo), pois ambos podem ocorrer simultaneamente. Não ocorrendo uma oposição entre os processos, significa que é possível que a conformação das vertentes esteja sendo mantida pelas características físico-hídricas dos horizontes diagnósticos do solo.

Para compreender as relações existentes entre solos e as formas de relevo, Tricart (1965) ressalta que, no geral, a pedogênese é um dos elementos da morfogênese, já que ela é capaz de modificar os mecanismos fundamentais da morfogênese. De modo contributivo, Pellerin (1992) destacam que a pedogênese é o motor da evolução do relevo, podendo inclusive direcioná-la. Portanto, modificando a sua forma intensificando ou retardando os processos.

É preciso ter em conta que não há necessariamente antagonismo entre pedogênese e morfogênese, os dois processos atuando, conjuntamente no estabelecimento do modelado. A continuidade dos horizontes do topo à base das colinas, mesmo com transformações laterais, indica o desencadeamento de processos solidários e simultâneos que prosseguem até agora; isso envolve também a ideia de convergência e de manutenção da funcionalidade. O paralelismo das organizações pedológicas com a forma da vertente é um indicador desse fato. É interessante perceber que se o relevo constituiu importante fator de formação dos solos, os resultados das pesquisas mostram que o solo é um importante fator de formação do relevo (QUEIROZ NETO, 2010).

Da combinação dos fatores de formação dos solos, dos processos de intemperismo e da pedogênese, resultam os diferentes tipos de solos existentes no meio ambiente. A partir dessa combinação os solos passam de coadjuvante para protagonista da evolução das vertentes, interferindo diretamente na morfogênese das mesmas. 


\section{METODOLOGIA}

\subsection{Localização e caracterização da área de estudo}

A área base do estudo está situada na região central do estado do Rio Grande do Sul, na Depressão Periférica Sul-rio-grandense (ROSS, 1996), próximo ao rebordo do Planalto da Bacia Sedimentar do Paraná, município de Santa Maria. Abrange parte do bairro Camobi e do distrito de Pains no município de Santa Maria. Nas áreas onde os processos erosivos esculpiram colinas alongadas em rochas da era Mesozoica da Bacia do Paraná, aparecem solos medianamente profundos como argissolos. Nas áreas de terraços e planícies fluviais, onde a flutuação do lençol freático, associado a conformação da topografia, imprime maior influência sobre os processos pedogenéticos ocorrem gleissolos e planossolos. A área sofreu significativas alterações na cobertura original da vegetação. Parte da área está inserida no domínio vegetal dos campos com capões e matas galerias (VIEIRA, 1984). O uso do solo predominante na área de estudo é lavouras temporárias de trigo, milho, arroz, soja e pecuária de corte e de leite.

A figura 1 mostra a localização das cinco vertentes modais da Formação Santa Maria (Membro Alemoa).

Bortoluzzi (1974) caracteriza a Formação Santa Maria, onde estão assentadas as vertentes em estudo, contribuindo assim para a caracterização da área:

A Formação Santa Maria compreende, na área de sua "seção tipo", uma fácies inferior e outra superior. A primeira (Fácies Passo das Tropas) é constituída por cerca de $25 \mathrm{~m}$ de arenitos grosseiros e conglomeráticos, contendo bolsões de conglomerados à base de clastos de argila siltosa vermelho, com restos da flora Dicroidium; o horizonte arenoso com siltitos e folhetos vermelhos, com fósseis vegetais, conchostráceos e restos de peixes. A superior (Fácies Alemoa) é composta por 50 a $55 \mathrm{~m}$ de lamitos vermelhos, contendo concreções calcíferas e uma fauna reptiliana característica (BORTOLUZZI, 1974, p.12). 
Figura 1 - Localização das cinco vertentes selecionadas na Formação Santa Maria (Membro Alemoa), no bairro Camobi e distrito de Pains, Santa Maria, região central do estado do Rio Grande do Sul

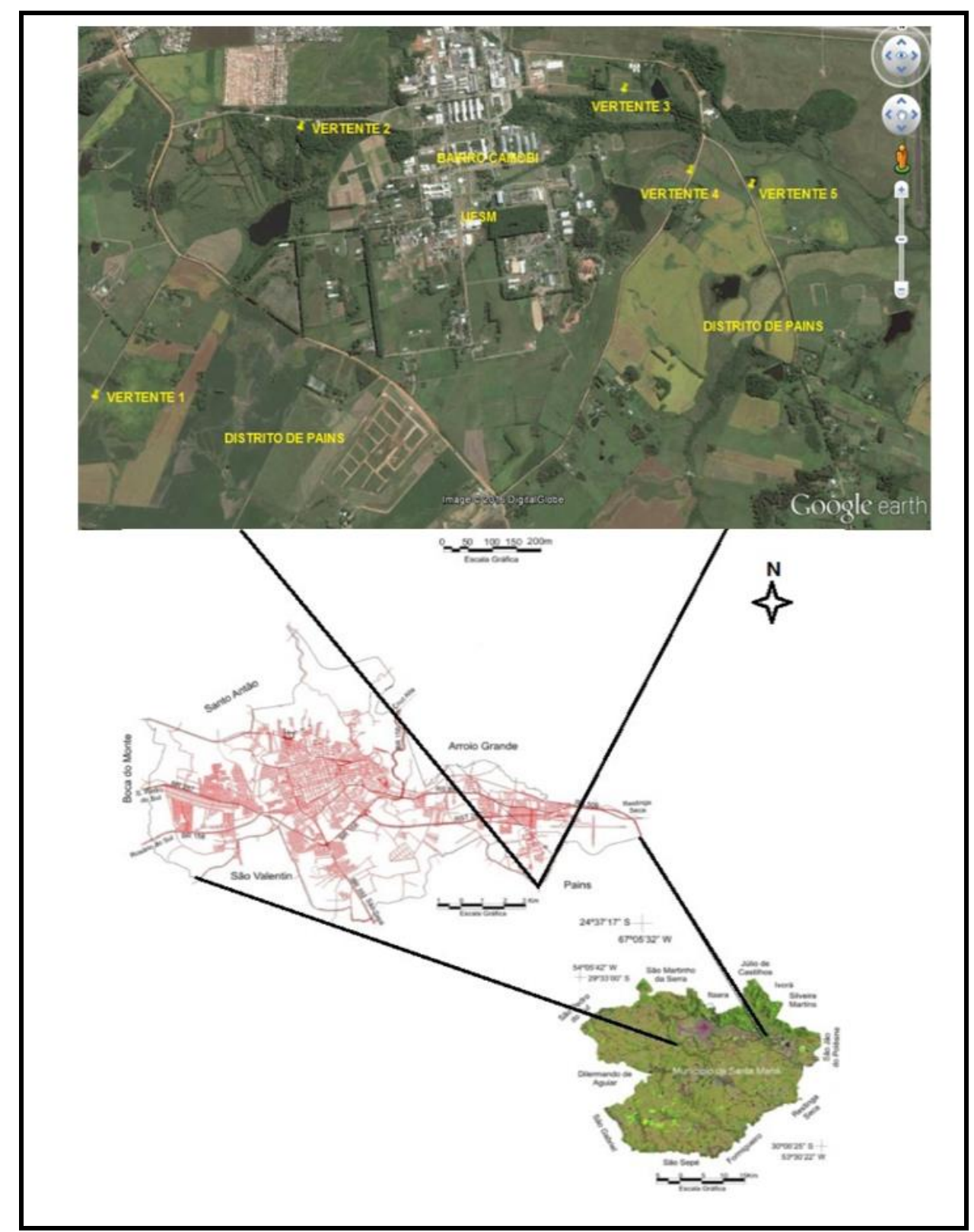

Fonte: Google Earth (Adaptado) em 23/09/2016

Sartori (2009) destaca que o Membro Alemoa, está representado por um lamito (siltito argiloso) de cor vermelha, compacto, maciço. Este Membro estratigráfico da sequência superior da Formação Santa Maria, caracteriza-se por apresentar contato com o estrato inferior em transição gradual de camadas de um arenito rosaavermelhado para um siltito argiloso, vermelho e maciço. Observa-se a presença de 
caliche e concreções carbonáticas irregulares descritas como calcretes e lentes arenosas se intercalam em direção ao topo. Este siltito argiloso constitui-se num importante aquiclude.

O clima da região de Santa Maria, com base na classificação de Köppen, enquadra-se como sendo mesotérmico brando Cfa. As precipitações são regulares durante todo o ano, não apresentando estação seca (AYOADE, 1986).

Sartori (2003), caracteriza o clima de Santa Maria, apresentando temperatura média no mês mais frio (julho) entre $10^{\circ} \mathrm{C}$ e $15^{\circ} \mathrm{C}$ e média das mínimas entre $6^{\circ} \mathrm{C}$ e $10^{\circ} \mathrm{C}$, devido a atuação do Anticiclone Polar Atlântico. Já no verão as temperaturas médias no mês mais quente (janeiro) são superiores a $22^{\circ} \mathrm{C}$, médias das máximas variando entre $28^{\circ} \mathrm{C}$ e $32^{\circ} \mathrm{C}$. As temperaturas médias anuais situam-se entre $18^{\circ} \mathrm{C}$ e $20^{\circ} \mathrm{C}$. As precipitações são regulares durante todo o ano, com médias anuais que variam entre 1500 a $1600 \mathrm{~mm} / \mathrm{ano}$.

\subsection{Orientação teórico metodológica}

A abordagem teórica do trabalho está assentada na hipótese de que os parâmetros físico-hídricos do solo influenciam na conformação das vertentes, constituindo-se importantes para avaliar os processos de evolução e manutenção da forma das mesmas. Sendo assim a pesquisa orienta-se visando a integração dos elementos dentro de um sistema. A figura 2 demonstra um sistema de processoresposta, constituindo a concepção metodológica abordada no estudo.

Para realização do trabalho, adotou-se o método hipotético-dedutivo, que segundo (Lakatos, Marconi, 2001, p.106), “inicia pela percepção de uma lacuna nos conhecimentos, acerca da qual formulam-se hipóteses e, pelo processo de inferências dedutivas, testa-se a predição da ocorrência de fenômenos abrangidos pela hipótese". De acordo com os objetivos do trabalho, adotou-se também como base teórico-metodológica a proposta de (Boulet, 1978), que trata da análise estrutural da cobertura pedológica. Busca-se assim, a compreensão da organização dos horizontes pedológicos bidimensionalmente em topossequências de vertentes, bem como as 
características dos mesmos, evidenciando a dinâmica da cobertura pedológica e a relação com os outros elementos da paisagem, dentre eles o substrato litológico e o clima.

Figura 2 - Sistema processo-resposta ilustrando a concepção metodológica abordada no estudo

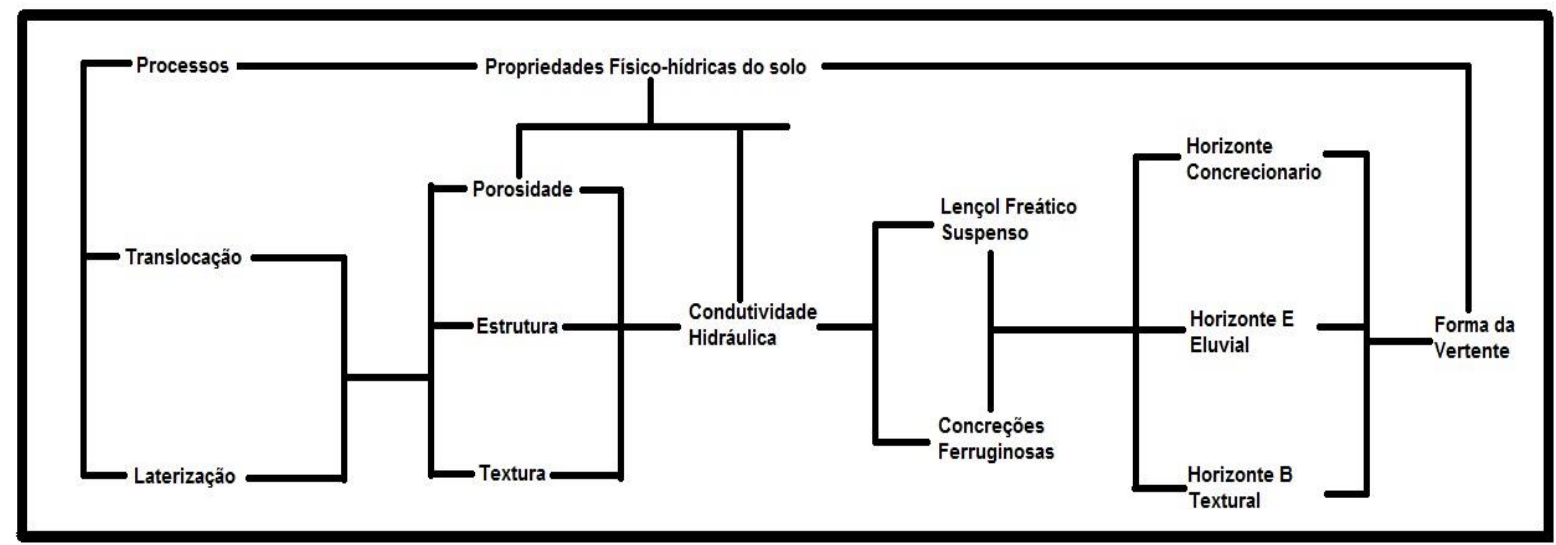

Fonte: Christofolletti, (1980) (Adaptado)

\subsection{Procedimentos técnicos operacionais}

Para atingir os objetivos propostos, assumiu-se como escala de observação os horizontes diagnósticos do solo, as topossequências de vertentes e a paisagem, seguindo-se os seguintes procedimentos (1) reconhecimento geral do comportamento das vertentes existentes na Depressão Periférica Sul-rio-grandense, na Formação Santa Maria, no município de Santa Maria/RS; (2) seleção das topossequências a serem caracterizadas; (3) detalhamento da estrutura da cobertura pedológica das vertentes, através da identificação e caracterização de perfis de solos em trincheiras e de sondagens a trado e (4) determinação dos parâmetros físicohídricos dos horizontes diagnósticos do solo nos perfis de solo, nas topossequências das vertentes da Formação Santa Maria. Seguindo esses princípios, Boulet e colaboradores (BOULET et al., 1982a, 1982b; RUELLAN et al., 1984; BOULET, 1988; QUEIROZ NETO, 1988) sistematizaram uma proposta de trabalho para estudos 
pedológicos de ultra detalhe com forte integração das relações pedologia-topografiaestratigrafia-hidrologia e a denominaram análise estrutural da cobertura pedológica.

Os parâmetros físico-hídricos do solo foram determinados a partir de amostras deformadas e indeformadas, que depois de coletadas foram destinadas para a realização dos ensaios em laboratório que determinaram: distribuição do tamanho de partículas, microporosidade, macroporosidade, porosidade total, diâmetro dos poros em diferentes tensões $(10 \mathrm{~cm}, 30 \mathrm{~cm}$ e $60 \mathrm{~cm})$, densidade aparente $(y d)$, densidade de partículas (ys) e condutividade hidráulica saturada (Ksat).

\section{RESULTADOS E DISCUSSÕES}

\subsection{Resultados obtidos para a vertente 1}

A vertente 1 selecionada para avaliação, que se apresenta como modal para o substrato litológico formado por rochas da Formação Santa Maria (Membro Alemoa), localiza-se entre as coordenadas geográficas: 2943'54"S e 5344'19"W. Situa-se na estrada para a colônia Pau a Pique, no distrito de Pains, próxima à área nova da Universidade Federal de Santa Maria.

Na figura 3, que ilustra essa vertente, é possível observar que ela apresenta perfil convexo-côncavo e mede, do topo até a base, cerca de 140 metros de comprimento, com ângulo de aproximadamente $8^{\circ}$, orientado para norte. No terço superior (setor convexo), foi aberta uma trincheira e, ao longo do perfil, foram realizadas quatro tradagens. A partir do terço médio inferior, constata-se que o perfil torna-se côncavo. Da trincheira cavada, foram descritas as características morfológicas do perfil de solo e coletadas as amostras deformadas e indeformadas, que permitiram a realização dos ensaios em laboratório. Na tabela 1, apresentam-se os resultados obtidos para os ensaios relativos à distribuição do tamanho de partículas e, na tabela 2, os resultados referentes aos parâmetros físico-hídricos dos horizontes diagnósticos descritos no perfil de solo. 
Figura 3 - Aspecto da área da vertente 1, selecionada como representativa das vertentes situadas sobre litologias da Formação Santa Maria (Membro Alemoa) no distrito de Pains e no bairro Camobi, município de Santa Maria, RS

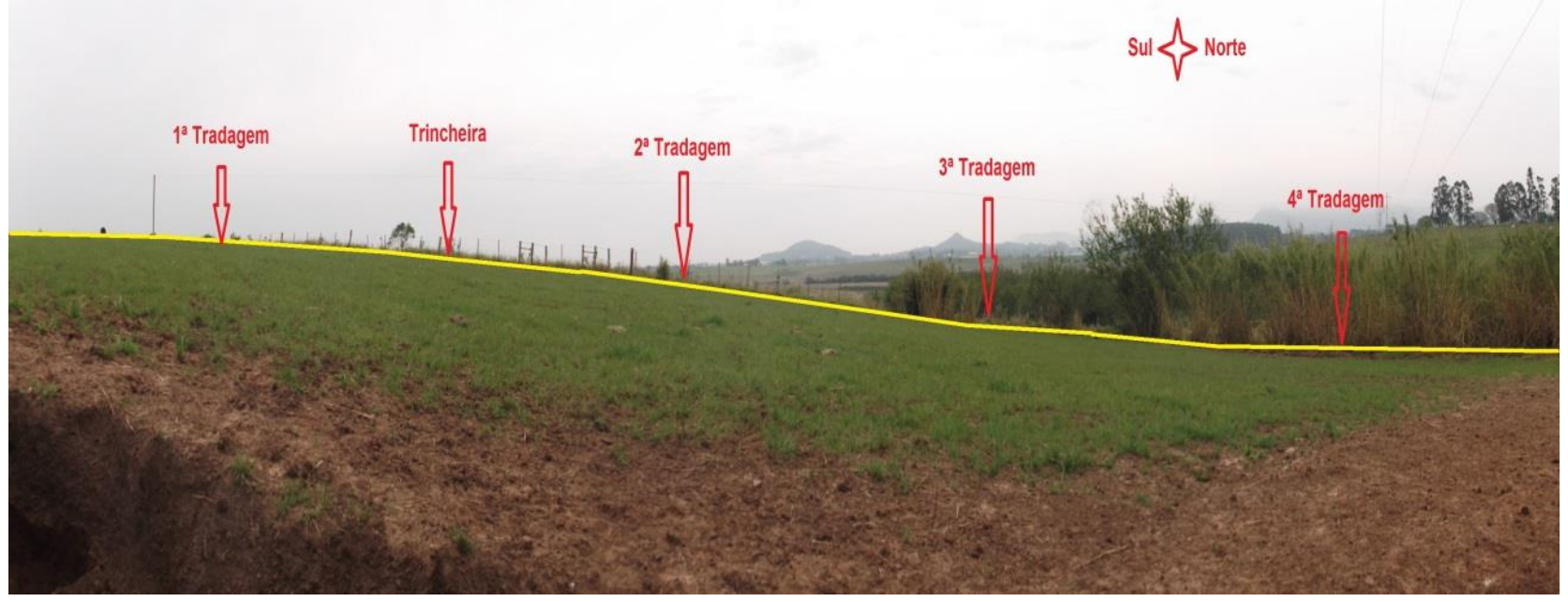

Fonte: Acervo particular dos autores (abril de 2015)

Tabela 1 - Distribuição do tamanho de partículas dos horizontes diagnósticos do perfil de solo da vertente 1, selecionada como modal da Formação Santa Maria (Membro Alemoa)

\begin{tabular}{l|c|c|c|c|c|c}
\hline \multicolumn{2}{l|}{$\begin{array}{c}\text { Horizontes } \\
\text { Diagnósticos }\end{array}$} & \multicolumn{5}{|c}{$\begin{array}{r}\text { Composição granulométrica da terra fina } \\
\text { (dispersão com NaOH) g.kg-1 }\end{array}$} \\
\hline & $\begin{array}{c}\text { Profundidade } \\
(\mathrm{cm})\end{array}$ & $\begin{array}{c}\text { Cascalho } \\
(20- \\
2 \mathrm{~mm})\end{array}$ & $\begin{array}{c}\text { Areia } \\
\text { grossa } \\
(2-0,2 \mathrm{~mm})\end{array}$ & $\begin{array}{c}\text { Areia fina } \\
(0,20- \\
0,05 \mathrm{~mm})\end{array}$ & $\begin{array}{c}\text { Silte } \\
(0,05,- \\
0,002 \mathrm{~mm})\end{array}$ & $\begin{array}{c}\text { Argila } \\
(<0,002 \mathrm{~m} \\
\mathrm{m})\end{array}$ \\
\hline Ap & $0-22$ & 232 & 169 & 161 & 436 & 234 \\
\hline Ac & $22-37$ & 700 & 238 & 110 & 346 & 310 \\
\hline Bt & $37-67$ & - & 251 & 38 & 275 & 661 \\
\hline BC & $67-114$ & - & 91 & 33 & 350 & 608 \\
\hline C & $114+$ & - & 55 & 37 & 299 & 659 \\
\hline
\end{tabular}

Fonte: Organização dos autores 
Tabela 2 - Parâmetros físico-hídricos dos horizontes diagnósticos do perfil de solo da vertente 1, selecionada como modal da Formação Santa Maria (Membro Alemoa)

\begin{tabular}{l|c|c|c|c|c|c|c|c|c}
\hline $\begin{array}{l}\text { Horizontes } \\
\text { Diagnósticos }\end{array}$ & $\%$ Sat & Micro & Macro & $\begin{array}{c}10 \\
\mathrm{~cm}\end{array}$ & $30 \mathrm{~cm}$ & $60 \mathrm{~cm}$ & $\gamma d$ & $\gamma s$ & $\begin{array}{c}\mathrm{Ksat} \\
(\mathrm{cm} / \mathrm{h})\end{array}$ \\
\hline $\mathrm{Ap}$ & 32,68 & 28,70 & 3,97 & - & - & 28,70 & 1,59 & 2,55 & 2,50 \\
\hline $\mathrm{Ac}$ & 38,78 & 23,28 & 15,49 & - & - & 23,28 & 1,87 & 2,61 & 45,22 \\
\hline $\mathrm{Bt}$ & 42,02 & 37,19 & 4,82 & - & - & 37,19 & 1,33 & 2,68 & 0,21 \\
\hline $\mathrm{BC}$ & 41,93 & 36,21 & 5,71 & - & - & 36,21 & 1,50 & 2,61 & 1,95 \\
\hline $\mathrm{C}$ & 43,38 & 40,67 & 2,71 & - & - & 40,67 & 1,40 & 2,66 & 1,98 \\
\hline
\end{tabular}

Mesa de tensão (\% Sat = porosidade total; Micro = microporosidade; Macro = macroporosidade; $10 \mathrm{~cm}=$ tensão dos poros na altura de $10 \mathrm{~cm} ; 30 \mathrm{~cm}$ = tensão dos poros na altura de $30 \mathrm{~cm}$ e $60 \mathrm{~cm}$ = tensão dos poros na altura de $60 \mathrm{~cm}) ; \gamma d=$ densidade aparente; $\gamma s=$ densidade de partículas e Ksat=condutividade hidráulica saturada.

Fonte: Organização dos autores

Os resultados obtidos para a distribuição do tamanho de partículas (tabela 1) mostram um incremento de argila em profundidade no perfil, nota-se também que esse incremento deriva da translocação dos horizontes superficiais Ap e Ac para os horizontes subsuperficiais Bt, BC e C, contribuindo assim para uma menor condutividade hidráulica. Outro fator que contribui para o aumento na condutividade hidráulica dos horizontes superficiais Ap e Ac é a presença de grande quantidade de cascalhos (concreções ferruginosas). Essas características propiciam a formação de fluxo lateral de água sobre o horizonte subsuperficial Bt, gerando uma zona de exfiltração de água no terço médio da vertente (setor côncavo) e influenciando a conformação do perfil convexo-côncavo da vertente. A figura 4 busca ilustrar esse mecanismo.

Observa-se, na figura da topossequência da vertente 1, que os horizontes apresentam-se mais ou menos homogêneos em relação à espessura ao longo da topossequência, indicando uma estabilidade entre pedogênese e morfogênese. 
Entretanto, nos horizontes superficiais Ap e Ac, onde a presença de concreções ferruginosas aparece em proporção significativa e gera uma camada endurecida, há uma variação na espessura desses horizontes. Isso contribui significativamente para a manutenção da atual forma do perfil (convexo-côncavo) dessa vertente.

Figura 4 - Topossequência da vertente 1, selecionada como modal para o substrato litológico da Formação Santa Maria (Membro Alemoa)

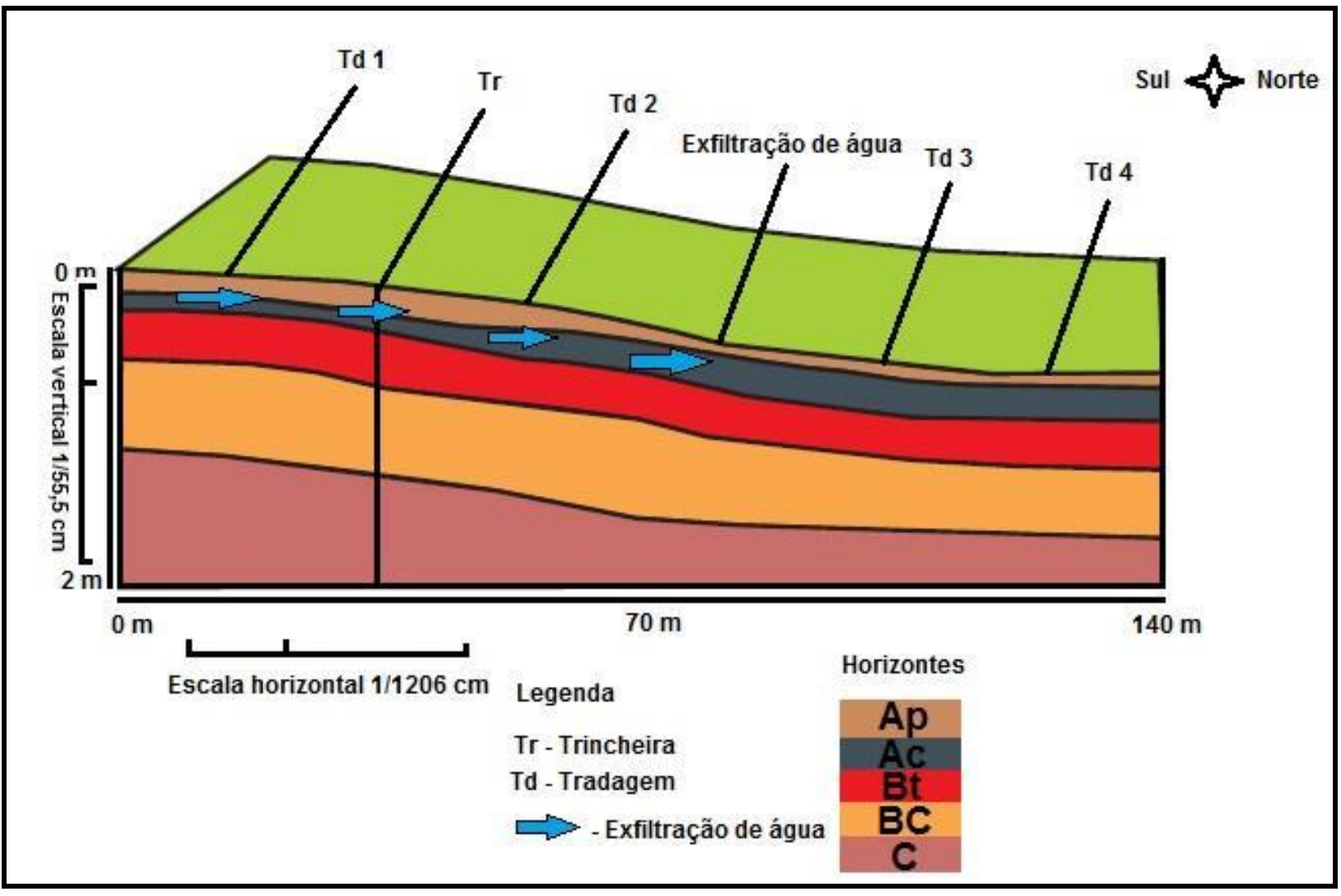

Fonte: Organização dos autores

\subsection{Resultados obtidos para a vertente 2}

A vertente 2 selecionada para avaliação, que se apresenta como modal para o substrato litológico formado por rochas da Formação Santa Maria (Membro Alemoa),

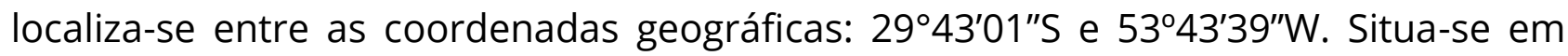
uma estrada próxima ao jardim botânico da Universidade Federal de Santa Maria. Na figura 5, que ilustra essa vertente, é possível observar que ela apresenta perfil 
convexo-côncavo e mede, do topo até a base, cerca de 110 metros de comprimento, com ângulo de aproximadamente $8^{\circ}$, orientado para norte. No terço superior (setor convexo), foi aberta uma trincheira e, ao longo do perfil, foram realizadas quatro tradagens. A partir do terço médio inferior, constata-se que o perfil torna-se côncavo. Da trincheira cavada, foram descritas as características morfológicas do perfil de solo e coletadas as amostras deformadas e indeformadas que, permitiram a realização dos ensaios em laboratório.

Na tabela 3, encontram-se os resultados obtidos para os ensaios relativos à distribuição do tamanho de partículas e, na tabela 4, os resultados referentes aos parâmetros físico-hídricos dos horizontes diagnósticos descritos no perfil de solo.

Figura 5 - Aspecto da área da vertente modal 2, selecionada como representativa das vertente situadas sobre litologias da Formação Santa Maria (Membro Alemoa) no distrito de Pains e no bairro Camobi, município de Santa Maria, RS

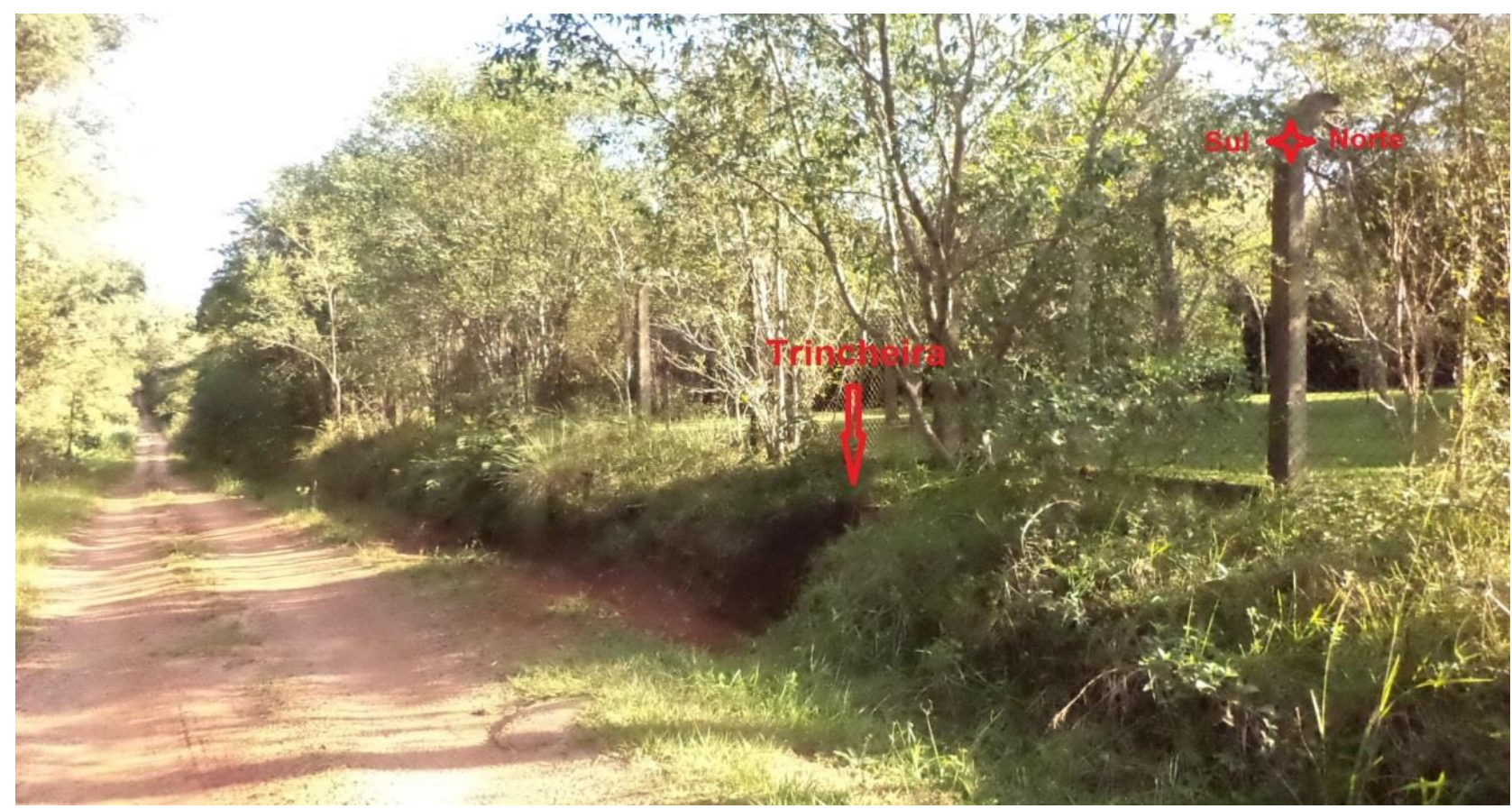

Fonte: Acervo particular dos autores (abril de 2015) 
3 - Distribuição do tamanho de partículas dos horizontes diagnósticos do perfil de solo da vertente 2, selecionada como modal da Formação Santa Maria (Membro Alemoa)

\begin{tabular}{l|c|c|c|c|c|c|c|c|c}
\hline $\begin{array}{l}\text { Horizontes } \\
\text { Diagnósticos }\end{array}$ & \% Sat & Micro & Macro & $10 \mathrm{~cm}$ & $30 \mathrm{~cm}$ & $60 \mathrm{~cm}$ & $\gamma d$ & $\gamma s$ & $\begin{array}{c}\text { Ksat } \\
\text { (cm/h) }\end{array}$ \\
\hline $\mathrm{A}$ & 17,71 & 21,41 & 6,55 & - & 22,86 & 21,41 & 1,89 & 2,53 & 0,22 \\
\hline $\mathrm{AB}$ & 16,68 & 22,79 & 6,94 & - & 25,86 & 22,79 & 1,92 & 2,53 & 0,42 \\
\hline $\mathrm{BA}$ & 17,30 & 27,49 & 5,09 & - & 26,50 & 27,49 & 1,93 & 2,65 & 0,42 \\
\hline $\mathrm{B}$ & 17,52 & 27,33 & 4,50 & - & 27,86 & 27,33 & 1,99 & 2,58 & 0,48 \\
\hline $\mathrm{BC}$ & 17,30 & 24,90 & 4,95 & - & 23,80 & 24,90 & 1,64 & 2,67 & 0,32 \\
\hline
\end{tabular}

Fonte: Organização dos autores

Tabela 4 - Parâmetros físico-hídricos dos horizontes diagnósticos do perfil de solo da vertente 2 selecionada como modal para o substrato litológico da Formação Santa Maria (Membro Alemoa)

\begin{tabular}{|c|c|c|c|c|c|c|}
\hline \multicolumn{2}{|c|}{$\begin{array}{l}\text { Horizontes } \\
\text { Diagnósticos }\end{array}$} & \multicolumn{5}{|c|}{$\begin{array}{l}\text { Composição granulométrica da terra fina } \\
\text { (dispersão com } \mathrm{NaOH} \text { ) g.kg-1 }\end{array}$} \\
\hline & $\begin{array}{c}\text { Profundida } \\
\text { de }(\mathrm{cm})\end{array}$ & $\begin{array}{l}\text { Cascalho } \\
(20-2 \mathrm{~mm})\end{array}$ & $\begin{array}{c}\text { Areia } \\
\text { grossa } \\
(2-0,2 \mathrm{~mm}) \\
\end{array}$ & $\begin{array}{c}\text { Areia fina } \\
(0,20- \\
0,05 \mathrm{~mm})\end{array}$ & $\begin{array}{c}\text { Silte } \\
(0,05,- \\
0,002 \mathrm{~mm})\end{array}$ & $\begin{array}{c}\text { Argila } \\
(<0,002 \mathrm{~m} \\
\mathrm{m})\end{array}$ \\
\hline A & $0-32$ & - & 70 & 202 & 394 & 334 \\
\hline$A B$ & $32-57$ & - & 53 & 151 & 314 & 482 \\
\hline $\mathrm{BA}$ & $57-86$ & - & 33 & 102 & 246 & 619 \\
\hline$B$ & $86-113$ & _ & 20 & 86 & 296 & 598 \\
\hline$B C$ & $113+$ & _- & 9 & 27 & 154 & 810 \\
\hline
\end{tabular}

Mesa de tensão $(\%$ Sat = porosidade total; Micro = microporosidade; Macro = macroporosidade; $10 \mathrm{~cm}=$ tensão dos poros na altura de $10 \mathrm{~cm} ; 30 \mathrm{~cm}$ = tensão dos poros na altura de $30 \mathrm{~cm}$ e $60 \mathrm{~cm}$ = tensão dos poros na altura de $60 \mathrm{~cm}$ ); $\gamma d$ = densidade aparente; $\gamma s=$ densidade de partículas e Ksat= condutividade hidráulica saturada Fonte: Análise laboratorial

Os resultados obtidos para a distribuição do tamanho de partículas (tabela 3) mostram um incremento de argila em profundidade no perfil. Observa-se também que essa translocação de argila dos horizontes diagnósticos superficiais $A$ e $A B$ para os horizontes subsuperficiais BA, B e BC não resulta em uma grande diferenciação nos valores da condutividade hidráulica (Ksat). Portanto, a textura dos horizontes permite uma melhor circulação da água nos horizontes superficiais por apresentarem 
uma grande quantidade de areia fina e silte. Já, nos horizontes subsuperficiais existe uma maior concentração de argila e isso promove a infiltração da água, que é direcionada para o terço médio da vertente por meio da ação da gravidade, onde o perfil torna-se então côncavo. Nesse sentido, o incremento de argila em profundidade no perfil do solo influi na condutividade hidráulica e, por consequência, na exfiltração que acontece no terço médio da vertente, promovendo uma concavidade nesse segmento. A figura 6 busca ilustrar esse mecanismo.

Figura 6 - Topossequência da vertente 2, selecionada como modal para o substrato litológico da Formação Santa Maria (Membro Alemoa)

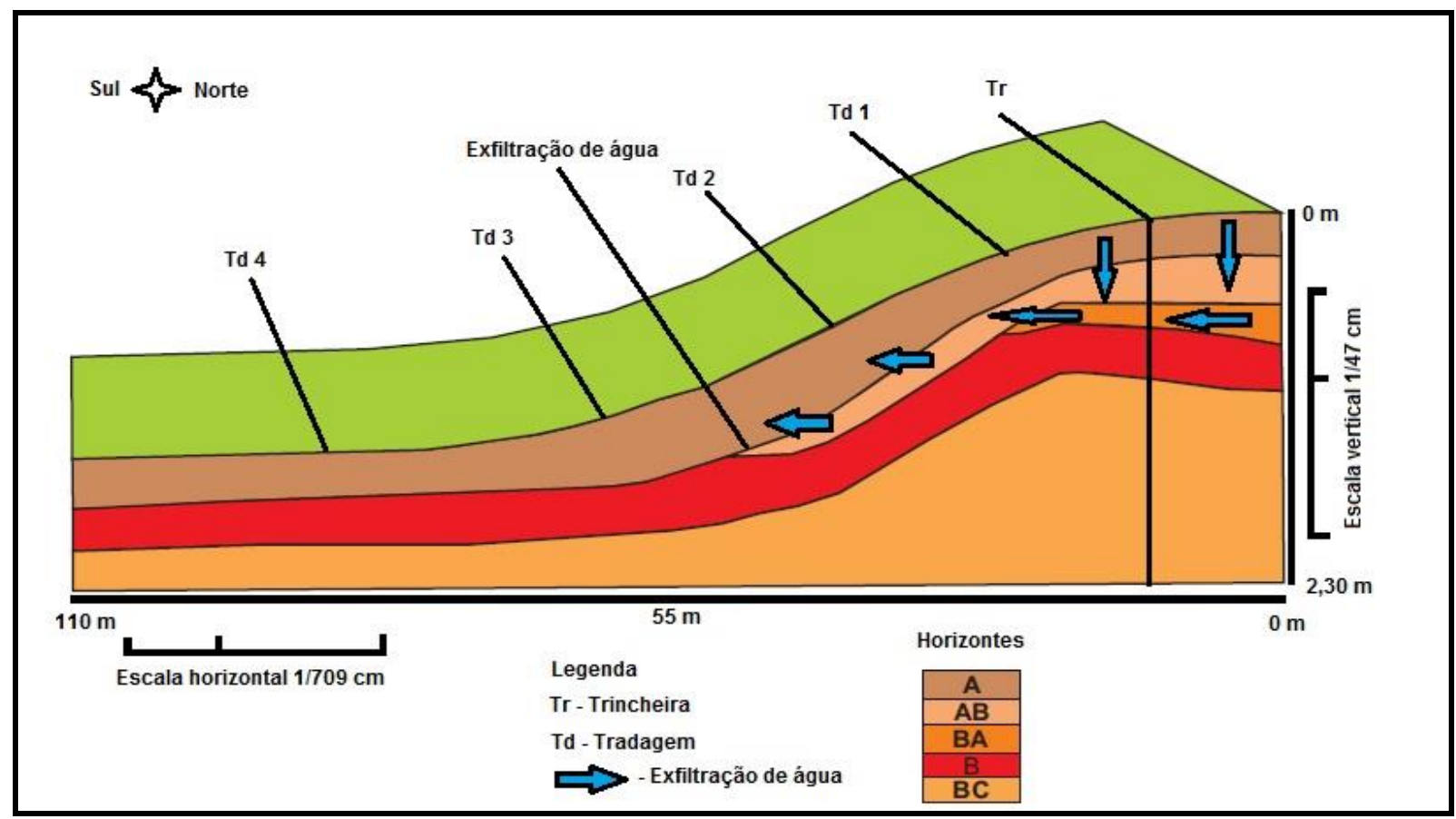

Fonte: organização dos autores

Portanto, as propriedades físico-hídricas do solo influenciam na conformação dessa vertente, situada sobre rochas da Formação Santa Maria (Membro Alemoa). Essa interferência pode ser destacada principalmente a partir dos valores obtidos na análise granulométrica e condutividade hidráulica. 


\subsection{Resultados obtidos para a vertente 3}

A vertente 3, selecionada como modal para o substrato litológico formado por rochas da Formação Santa Maria (Membro Alemoa), está localizada entre as

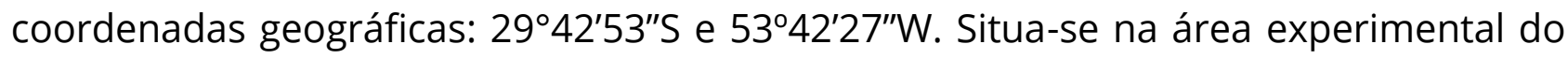
Centro de Ciências Rurais, da Universidade Federal de Santa Maria. Na figura 7, que ilustra essa vertente, é possível observar que ela apresenta perfil convexo-côncavo e mede, do topo até a base, cerca de 151 metros de comprimento, com ângulo de aproximadamente $8^{\circ}$, orientado para sul. No terço superior (setor convexo), foi aberta uma trincheira e, ao longo do perfil, foram realizadas quatro tradagens. A partir do terço médio inferior, observa-se que o perfil torna-se côncavo. Da trincheira cavada, foram descritas as características morfológicas do perfil de solo e coletadas as amostras deformadas e indeformadas, para a realização dos ensaios em laboratório.

$\mathrm{Na}$ tabela 5, constam os resultados obtidos para os ensaios relativos à distribuição do tamanho de partículas e, na tabela 6, os resultados referentes aos parâmetros físico-hídricos dos horizontes diagnósticos descritos no perfil de solo.

Figura 9 - Aspecto da área da vertente 3, selecionada como representativa das vertentes situadas sobre litologias da Formação Santa Maria (Membro Alemoa) no distrito de Pains e no bairro Camobi, município de Santa Maria, RS

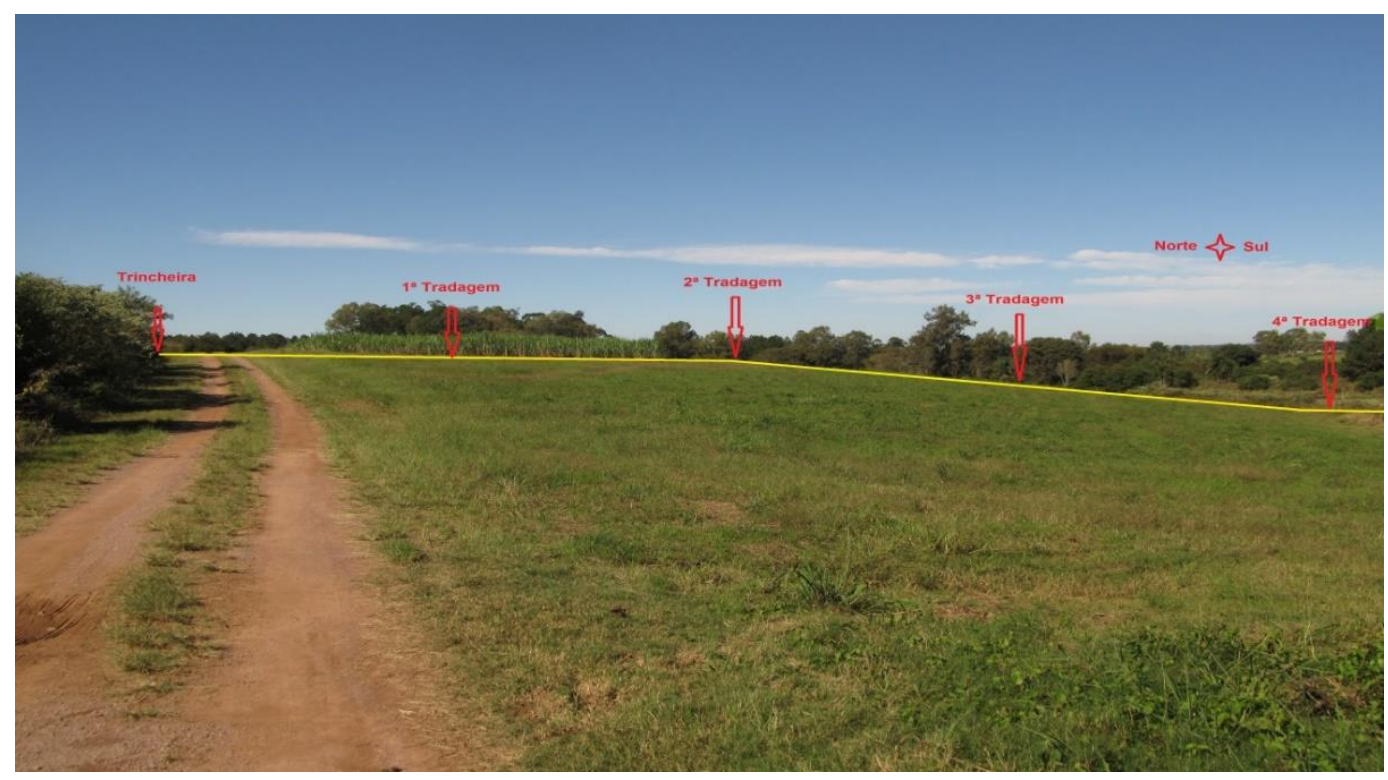


Tabela 5 - Distribuição do tamanho de partículas dos horizontes diagnósticos do perfil de solo da vertente 3, selecionada como modal da Formação Santa Maria (Membro Alemoa)

\begin{tabular}{l|c|c|c|c|c|c}
\hline $\begin{array}{l}\text { Horizontes } \\
\text { Diagnósticos }\end{array}$ & \multicolumn{5}{|c}{$\begin{array}{r}\text { Composição granulométrica da terra fina } \\
\text { (dispersão com NaOH) g.kg-1 }\end{array}$} \\
\hline & $\begin{array}{c}\text { Profundida } \\
\text { de (cm) }\end{array}$ & $\begin{array}{c}\text { Cascalho } \\
(20-2 \mathrm{~mm})\end{array}$ & $\begin{array}{c}\text { Areia grossa } \\
(2-0,2 \mathrm{~mm})\end{array}$ & $\begin{array}{c}\text { Areia fina } \\
(0,20-0,05 \mathrm{~mm})\end{array}$ & $\begin{array}{c}\text { Silte } \\
(0,05,-0,002 \mathrm{~mm})\end{array}$ & $\begin{array}{c}\text { Argila } \\
(<0,002 \mathrm{~mm})\end{array}$ \\
\hline A & $0-51$ & 0,5 & 154 & 421 & 315 & 106 \\
\hline AE & $51-73$ & 0,9 & 117 & 424 & 353 & 104 \\
\hline E & $73-88$ & 13,6 & 108 & 406 & 390 & 70 \\
\hline EB & $88-110$ & 25,4 & 86 & 350 & 394 & 135 \\
\hline BE & $110-139$ & 24,5 & 57 & 151 & 293 & 355 \\
\hline B & $139+$ & 35 & 60 & 251 & 281 & 375 \\
\hline
\end{tabular}

Fonte: Organização dos autores

Tabela 6 - Parâmetros físico-hídricos dos horizontes diagnósticos do perfil de solo da vertente 3, selecionada como modal da Formação Santa Maria (MembroAlemoa)

\begin{tabular}{l|c|c|c|c|c|c|c|c|c}
\hline $\begin{array}{l}\text { Horizontes } \\
\text { Diagnósticos }\end{array}$ & $\%$ Sat & Micro & Macro & $10 \mathrm{~cm}$ & $30 \mathrm{~cm}$ & $60 \mathrm{~cm}$ & $\gamma d$ & $\gamma s$ & $\begin{array}{c}\text { Ksat } \\
(\mathrm{cm} / \mathrm{h})\end{array}$ \\
\hline $\mathrm{A}$ & 37,00 & 28,52 & 8,48 & 34,98 & 31,83 & 28,52 & 1,54 & 2,61 & 24,19 \\
\hline $\mathrm{AE}$ & 39,14 & 29,24 & 9,90 & 36,21 & 32,87 & 29,24 & 1,62 & 2,50 & 10,75 \\
\hline $\mathrm{E}$ & 34,36 & 27,72 & 6,64 & 31,64 & 29,25 & 27,72 & 1,82 & 2,28 & 3,38 \\
\hline $\mathrm{EB}$ & 41,38 & 32,65 & 8,73 & 38,16 & 34,13 & 32,65 & 1,50 & 2,59 & 32,31 \\
\hline $\mathrm{BE}$ & 46,33 & 38,62 & 7,71 & 42,30 & 40,01 & 38,62 & 1,38 & 2,56 & 9,52 \\
\hline $\mathrm{B}$ & 46,64 & 41,30 & 5,34 & 46,07 & 42,38 & 41,30 & 1,46 & 2,42 & 0,06 \\
\hline
\end{tabular}

tensão (\% Sat = porosidade total; Micro = microporosidade; Macro = macroporosidade; $10 \mathrm{~cm}=$ tensão dos poros na altura de $10 \mathrm{~cm} ; 30 \mathrm{~cm}=$ tensão dos poros na altura de $30 \mathrm{~cm} \mathrm{e} 60 \mathrm{~cm}=$ tensão dos poros na altura de $60 \mathrm{~cm}$ ); $\gamma d=$ densidade aparente; $\gamma s$ = densidade de partículas e Ksat= condutividade hidráulica saturada

Fonte: Organização dos autores

Os resultados obtidos para a distribuição do tamanho de partículas (tabela 5) mostram que há uma translocação de argila dos horizontes diagnósticos superficiais A, AE, E e EB para os horizontes subsuperficiais BE e B. Observa-se, na tabela 6, que os maiores valores de macroporosidade correspondem à maior condutividade hidráulica. 
A concentração de argila nos horizontes subsuperficiais BE e B causa uma saturação em subsuperfície, junto ao horizonte $B$, e, a partir disso, promove a ocorrência de fluxo lateral da água infiltrada. Assim, motiva uma exfiltração, que acontece a partir do terço médio inferior desse vertente. Nesse segmento, o perfil torna-se côncavo. A figura 10 procura ilustrar esse processo.

Figura 10 - Topossequência da vertente 3, selecionada como modal para o substrato litológico da Formação Santa Maria (Membro Alemoa)

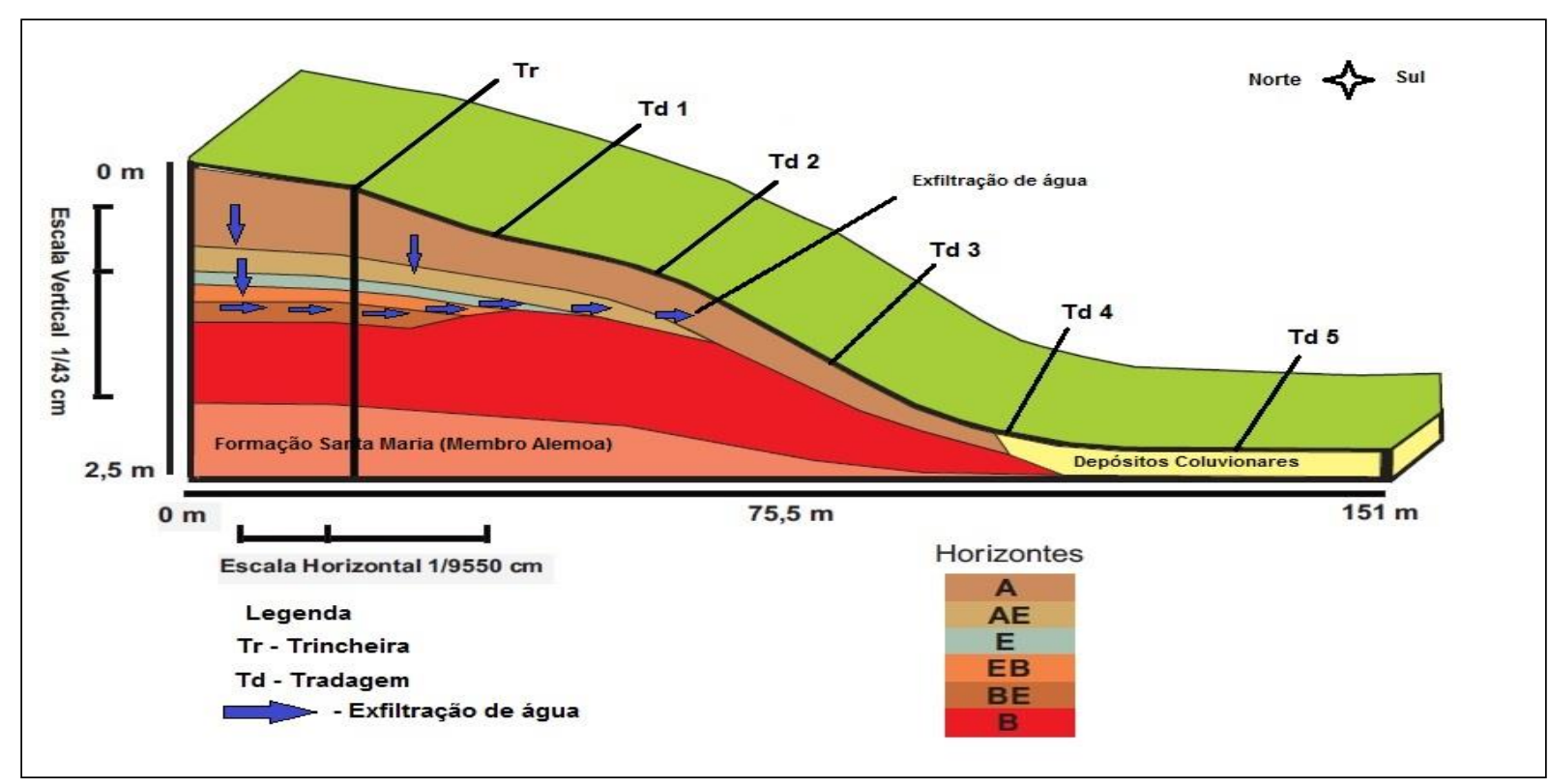

Fonte: Organização dos autores

Também ocorre a presença de cascalhos (concreções ferruginosas) nos horizontes diagnósticos, que influi na circulação da água dentro do perfil de solo. Observa-se ainda que a exfiltração aconteça a partir do terço médio inferior da vertente. Isso provavelmente está relacionado à presença dessas concreções, que mantém o segmento convexo, e à exfiltração proporcionada pela maior condutividade hidráulica do horizonte EB no segmento côncavo. Portanto, as propriedades físico-hídricas do solo influenciam na conformação do perfil convexocôncavo nessa vertente. 


\subsection{Resultados obtidos para a vertente 4}

A vertente 4 selecionada para avaliação, que se apresenta como modal para o substrato litológico formado por rochas da Formação Santa Maria (Membro Alemoa), localiza-se entre as coordenadas geográficas: $29^{\circ} 43^{\prime} 08^{\prime \prime S}$ e 5342'09'W, a leste do campus da Universidade Federal de Santa Maria, em um afloramento rochoso, ao lado da estrada municipal Pedro Fernandes da Silveira.

Figura 11 - Aspecto da área da vertente modal 4, selecionada como representativa das vertentes situadas sobre litologias da Formação Santa Maria (Membro Alemoa) no distrito de Pains e no bairro Camobi, município de Santa Maria, RS

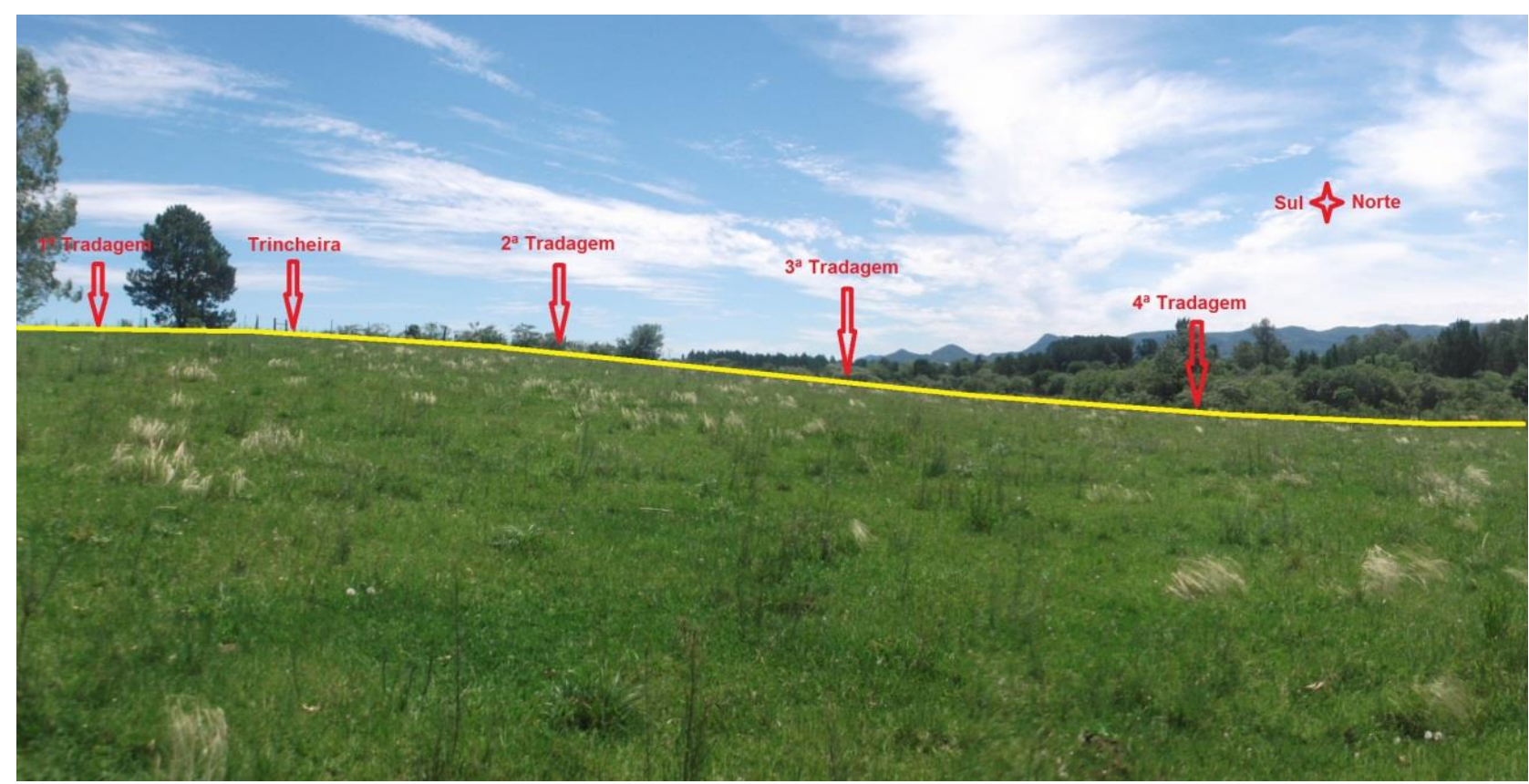

Fonte: Acervo dos autores (setembro de 2015)

Na figura 11, que ilustra essa vertente, é possível observar que ela apresenta perfil convexo-côncavo e mede, do topo até a base, cerca de 360 metros de comprimento, com ângulo de aproximadamente $8^{\circ}$, orientado para norte. No terço superior (setor convexo), foi aberta uma trincheira e, ao longo do perfil, foram realizadas quatro tradagens. A partir da trincheira cavada, foram descritas as características morfológicas do perfil de solo e coletadas as amostras deformadas e indeformadas, que serviram para a realização dos ensaios em laboratório. 
Na tabela 7, apresentam-se os resultados obtidos para os ensaios relativos à distribuição do tamanho de partículas e, na tabela 8, os resultados referentes aos parâmetros físico-hídricos dos horizontes diagnósticos descritos no perfil de solo.

Tabela 7 - Distribuição do tamanho de partículas dos horizontes diagnósticos do perfil de solo da vertente 4, selecionada como modal da Formação Santa Maria (Membro Alemoa) Fonte: Organização dos autores

\begin{tabular}{l|c|c|c|c|c|c}
\hline \multicolumn{5}{l|}{$\begin{array}{r}\text { Horizontes } \\
\text { Diagnósticos }\end{array}$} & \multicolumn{5}{|c}{$\begin{array}{l}\text { Composição granulométrica da terra fina } \\
\text { (dispersão com NaOH) g.kg-1 }\end{array}$} \\
\hline & $\begin{array}{c}\text { Profundida } \\
\text { de } \\
(\mathrm{cm})\end{array}$ & $\begin{array}{c}\text { Cascalho } \\
(20-2 \mathrm{~mm})\end{array}$ & $\begin{array}{c}\text { Areia grossa } \\
(2-0,2 \mathrm{~mm})\end{array}$ & $\begin{array}{c}\text { Areia fina } \\
(0,20-0,05 \mathrm{~mm})\end{array}$ & $\begin{array}{c}\text { Silte } \\
(0,05,-0,002 \mathrm{~mm})\end{array}$ & $\begin{array}{c}\text { Argila } \\
(<0,002 \mathrm{~mm})\end{array}$ \\
\hline $\mathrm{A}$ & $0-80$ & - & 243 & 327 & 266 & 163 \\
\hline $\mathrm{E}$ & $80-115$ & - & 187 & 343 & 329 & 140 \\
\hline $\mathrm{Bf}$ & $115-145$ & 483 & 140 & 257 & 249 & 356 \\
\hline $\mathrm{Bt}$ & $145-190$ & - & 120 & 214 & 192 & 471 \\
\hline $\mathrm{BC}$ & $190+$ & - & 120 & 211 & 230 & 438 \\
\hline
\end{tabular}

Tabela 8 - Parâmetros físico-hídricos dos horizontes diagnósticos do perfil de solo da vertente 4, selecionada como modal para o substrato litológico da Formação Santa Maria (Membro Alemoa)

\begin{tabular}{l|c|c|c|c|c|c|c|c|c}
\hline $\begin{array}{l}\text { Horizontes } \\
\text { Diagnósticos }\end{array}$ & $\%$ Sat & Micro & Macro & $10 \mathrm{~cm}$ & $30 \mathrm{~cm}$ & $60 \mathrm{~cm}$ & $\gamma d$ & $\gamma s$ & $\begin{array}{c}\text { Ksat } \\
(\mathrm{cm} / \mathrm{h})\end{array}$ \\
\hline $\mathrm{A}$ & 43,47 & 29,01 & 14,45 & 3,88 & 9,86 & 14,45 & 1,46 & 2,63 & 4,12 \\
\hline $\mathrm{E}$ & 33,35 & 26,85 & 6,50 & 3,39 & 5,34 & 6,50 & 1,56 & 2,65 & 5,87 \\
\hline $\mathrm{Bf}$ & 45,05 & 38,53 & 6,52 & 3,38 & 5,54 & 6,52 & 1,75 & 2,67 & 11,70 \\
\hline $\mathrm{Bt}$ & 48,34 & 43,99 & 4,35 & 1,68 & 3,09 & 4,35 & 1,46 & 2,74 & 0,62 \\
\hline $\mathrm{BC}$ & 49,67 & 42,62 & 7,05 & 3,27 & 5,74 & 7,05 & 1,56 & 2,69 & 1,68 \\
\hline
\end{tabular}

Mesa de tensão (\% Sat = porosidade total; Micro = microporosidade; Macro = macroporosidade; $10 \mathrm{~cm}=$ tensão dos poros na altura de $10 \mathrm{~cm} ; 30 \mathrm{~cm}=$ tensão dos poros na altura de $30 \mathrm{~cm}$ e $60 \mathrm{~cm}$ = tensão dos poros na altura de $60 \mathrm{~cm}$ ); $\gamma d$ = densidade aparente; $\gamma s=$ densidade de partículas e Ksat= condutividade hidráulica saturada Fonte: Organização dos autores

Os resultados obtidos para a distribuição do tamanho de partículas (tabela 7) mostram há translocação de argila dos horizontes superficiais A, E e Bf para os horizontes subsuperficiais Bt e BC. Percebe-se que o mais argiloso dos horizontes (Bt), 
impede a infiltração de água, formando, acima dele, um fluxo lateral de água. Acima do horizonte Bt está o horizonte Bf, apresentando como principal característica a presença de cascalhos (concreções ferruginosas), que proporcionam maior condutividade hidráulica (tabela 8). Isso contribui para que ocorra o mecanismo de exfiltração de água no terço médio da vertente, tornando o segmento do perfil côncavo. A figura 12 ilustra esse processo.

Figura 12 - Topossequência da vertente 4, selecionada como modal para o substrato litológico da Formação Santa Maria (Membro Alemoa)

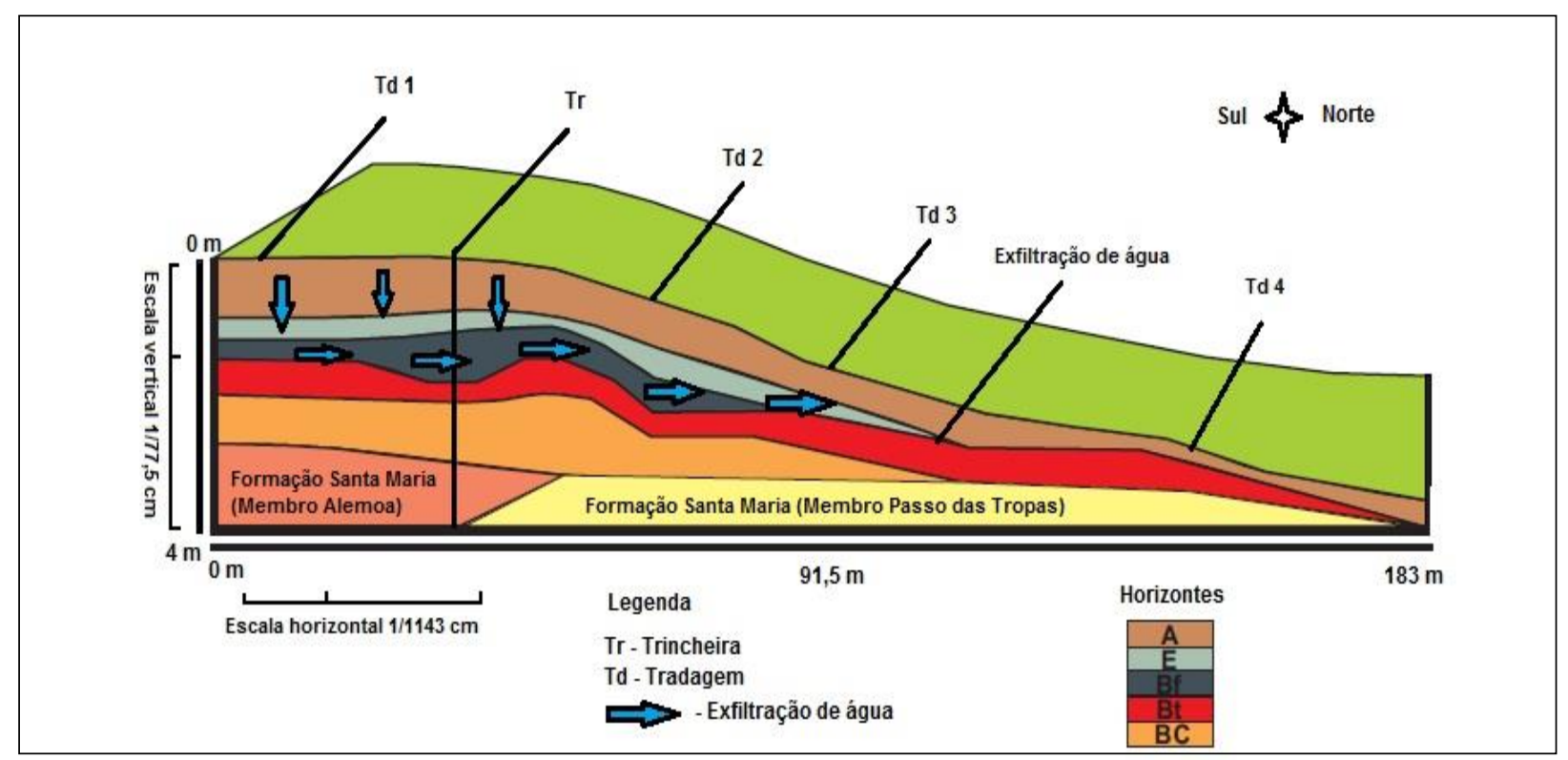

Fonte: Organização dos autores

A presença dos horizontes $\mathrm{E}$ e Bf, que se encontram apenas no terço superior e médio da vertente, influenciam a circulação hídrica e, por consequência, a evolução do perfil convexo-côncavo da vertente. A maior concavidade no segmento inferior da vertente possivelmente está relacionada ao mecanismo de exfiltração que acontece nesse segmento, conforme ilustrado na figura 12.

\subsection{Resultados obtidos para a vertente 5}

A vertente 5 selecionada para avaliação, que se apresenta como modal para o substrato litológico formado por rochas da Formação Santa Maria (Membro Alemoa), 
localiza-se entre as coordenadas geográficas: $29^{\circ} 43^{\prime} 26^{\prime \prime} \mathrm{S}$ e $53^{\circ} 41^{\prime \prime} 25^{\prime \prime} \mathrm{W}$. Situa-se a leste do campus da Universidade Federal de Santa Maria, em um afloramento ao lado da estrada secundária que dá cesso ao interior do município de Santa Maria.

Figura 13 - Aspecto da área da vertente modal 5, selecionada como representativa das vertentes situadas sobre litologias da Formação Santa Maria (Membro Alemoa) no distrito de Pains e no bairro Camobi, município de Santa Maria, RS

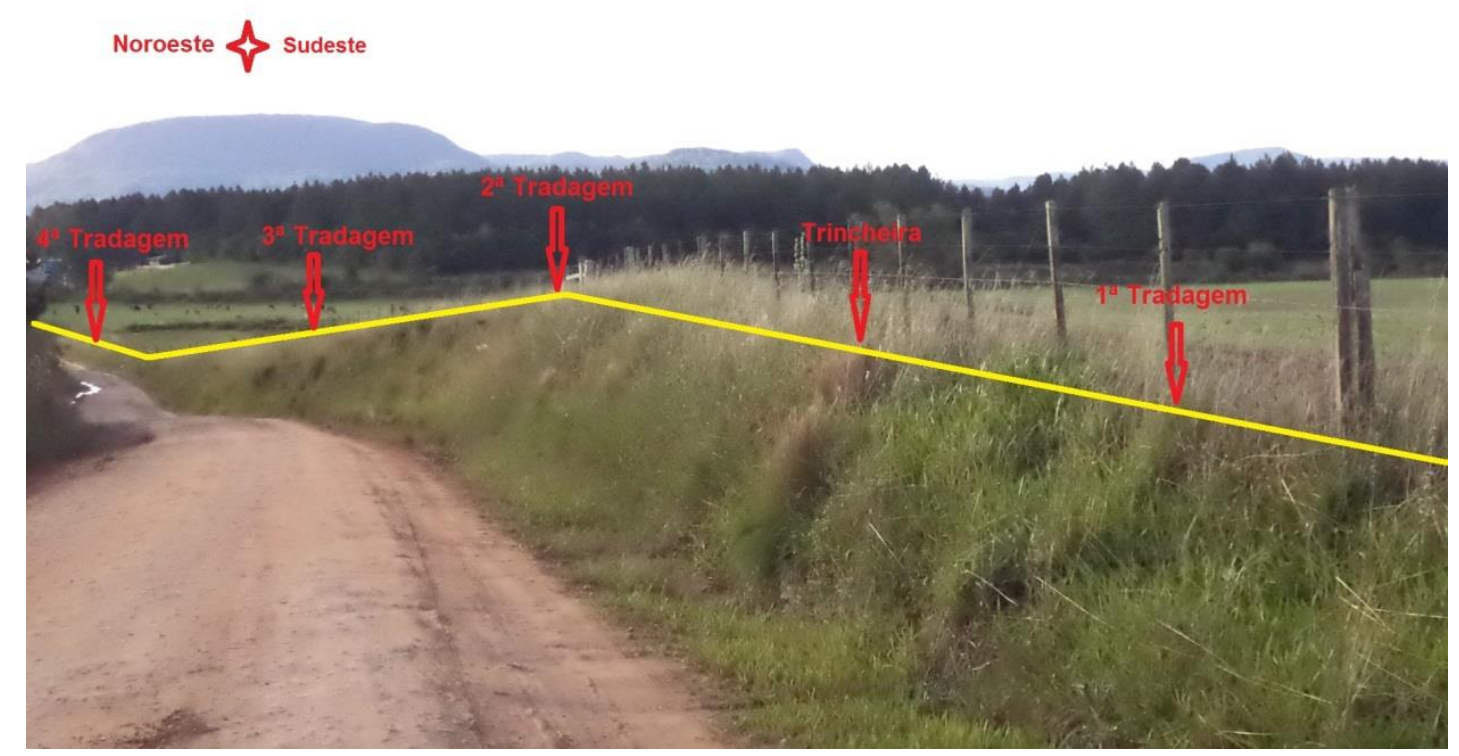

Fonte: Acervo particular dos autores (novembro de 2015)

Na figura 13, que ilustra essa vertente, é possível observar que ela apresenta perfil convexo-côncavo e mede, do topo até a base, cerca de 280 metros de comprimento, com ângulo de aproximadamente $8^{\circ}$, orientado para nordeste. No terço superior (setor convexo), foi aberta uma trincheira e, ao longo do perfil, foram realizadas quatro tradagens. A partir da trincheira cavada, foram descritas as características morfológicas do perfil do solo e coletadas amostras deformadas e indeformadas, para a realização dos ensaios em laboratório. Na tabela 9, encontramse os resultados obtidos para os ensaios relativos à distribuição do tamanho de partículas e, na tabela 10, os resultados referentes aos parâmetros físico-hídricos dos horizontes diagnósticos descritos no perfil de solo. 
Tabela 9 - Distribuição do tamanho de partículas dos horizontes diagnósticos do perfil de solo da vertente 5, selecionada como modal da Formação Santa Maria (Membro Alemoa)

\begin{tabular}{l|c|c|c|c|c|c}
\hline \multirow{2}{*}{$\begin{array}{l}\text { Horizontes } \\
\text { Diagnósticos }\end{array}$} & \multicolumn{5}{c}{$\begin{array}{c}\text { Composição granulométrica da terra fina } \\
\text { (dispersão com NaOH) g.kg-1 }\end{array}$} \\
\hline & $\begin{array}{c}\text { Profundidade } \\
(\mathrm{cm})\end{array}$ & $\begin{array}{c}\text { Cascalho } \\
(20-2 \mathrm{~mm})\end{array}$ & $\begin{array}{c}\text { Areia grossa } \\
(2-0,2 \mathrm{~mm})\end{array}$ & $\begin{array}{c}\text { Areia fina } \\
(0,20-0,05 \mathrm{~mm})\end{array}$ & $\begin{array}{c}\text { Silte } \\
(0,05,-0,002 \mathrm{~mm})\end{array}$ & $\begin{array}{c}\text { Argila } \\
(<0,002 \\
\mathrm{mm})\end{array}$ \\
\hline $\mathrm{A}$ & $0-35$ & - & 189 & 338 & 256 & 216 \\
\hline $\mathrm{AE}$ & $35-58$ & - & 135 & 366 & 300 & 197 \\
\hline $\mathrm{E}$ & $58-82$ & - & 171 & 331 & 306 & 190 \\
\hline $\mathrm{BE}$ & $82-104$ & - & 100 & 204 & 250 & 445 \\
\hline $\mathrm{B}$ & $104-141$ & - & 143 & 227 & 209 & 420 \\
\hline $\mathrm{BC}$ & $141+$ & & 132 & 241 & 230 & 396 \\
\hline
\end{tabular}

Fonte: Organização dos autores

Tabela 10 - Parâmetros físico-hídricos dos horizontes diagnósticos do perfil de solo da vertente 5, selecionada como modal para o substrato litológico da Formação Santa Maria (Membro Alemoa)

\begin{tabular}{l|c|c|c|c|c|c|c|c|c}
\hline $\begin{array}{l}\text { Horizontes } \\
\text { Diagnósticos }\end{array}$ & \% Sat & Micro & Macro & $10 \mathrm{~cm}$ & $30 \mathrm{~cm}$ & $60 \mathrm{~cm}$ & $\gamma d$ & $\gamma s$ & $\begin{array}{c}\text { Ksat } \\
(\mathrm{cm} / \mathrm{h})\end{array}$ \\
\hline $\mathrm{A}$ & 42,93 & 29,35 & 13,57 & 38,18 & 34,81 & 29,35 & 1,32 & 2,61 & 8,64 \\
\hline $\mathrm{AE}$ & 44,34 & 29,41 & 14,93 & 39,74 & 35,81 & 29,41 & 1,50 & 2,61 & 11,36 \\
\hline $\mathrm{E}$ & 37,32 & 29,01 & 8,30 & 35,02 & 32,82 & 29,01 & 1,51 & 2,66 & 5,46 \\
\hline $\mathrm{BE}$ & 45,34 & 39,86 & 5,47 & 43,68 & 42,29 & 39,86 & 1,32 & 2,66 & 0,10 \\
\hline $\mathrm{B}$ & 47,31 & 41,66 & 5,64 & 45,19 & 43,92 & 41,66 & 1,39 & 2,67 & 0,05 \\
\hline $\mathrm{BC}$ & 46,90 & 41,60 & 5,30 & 45,00 & 43,73 & 41,60 & 1,40 & 2,61 & 2,11 \\
\hline
\end{tabular}

Mesa de tensão (\% Sat = porosidade total; Micro = microporosidade; Macro = macroporosidade; $10 \mathrm{~cm}=$ tensão dos poros na altura de $10 \mathrm{~cm} ; 30 \mathrm{~cm}$ = tensão dos poros na altura de $30 \mathrm{~cm}$ e $60 \mathrm{~cm}$ = tensão dos poros na altura de $60 \mathrm{~cm}) ; \gamma d=$ densidade aparente; $\gamma s$ = densidade de partículas e Ksat=condutividade hidráulica saturada Fonte: Organização dos autores 
Os resultados obtidos para a distribuição do tamanho de partículas (tabela 9) mostram relação com os resultados obtidos para os parâmetros físico-hídricos (tabela 10). Os horizontes diagnósticos superficiais $A, A E$ e E apresentam maior quantidade de areia, de silte e de macroporos, responsáveis por uma maior condutividade hidráulica. Já os horizontes diagnósticos subsuperficiais BE, B e BC apresentam uma maior quantidade de argila e de macroporos, que resultam numa menor condutividade hidráulica. Essas características refletem o processo de translocação das argilas dos horizontes superficiais para os subsuperficiais. A figura 14 procura ilustrar o processo de exfiltração que ocorre no segmento médio inferior da vertente, a partir da interface do horizonte BE e B.

Figura 14 - Topossequência da vertente 5, selecionada como modal para o substrato litológico da Formação Santa Maria (Membro Alemoa)

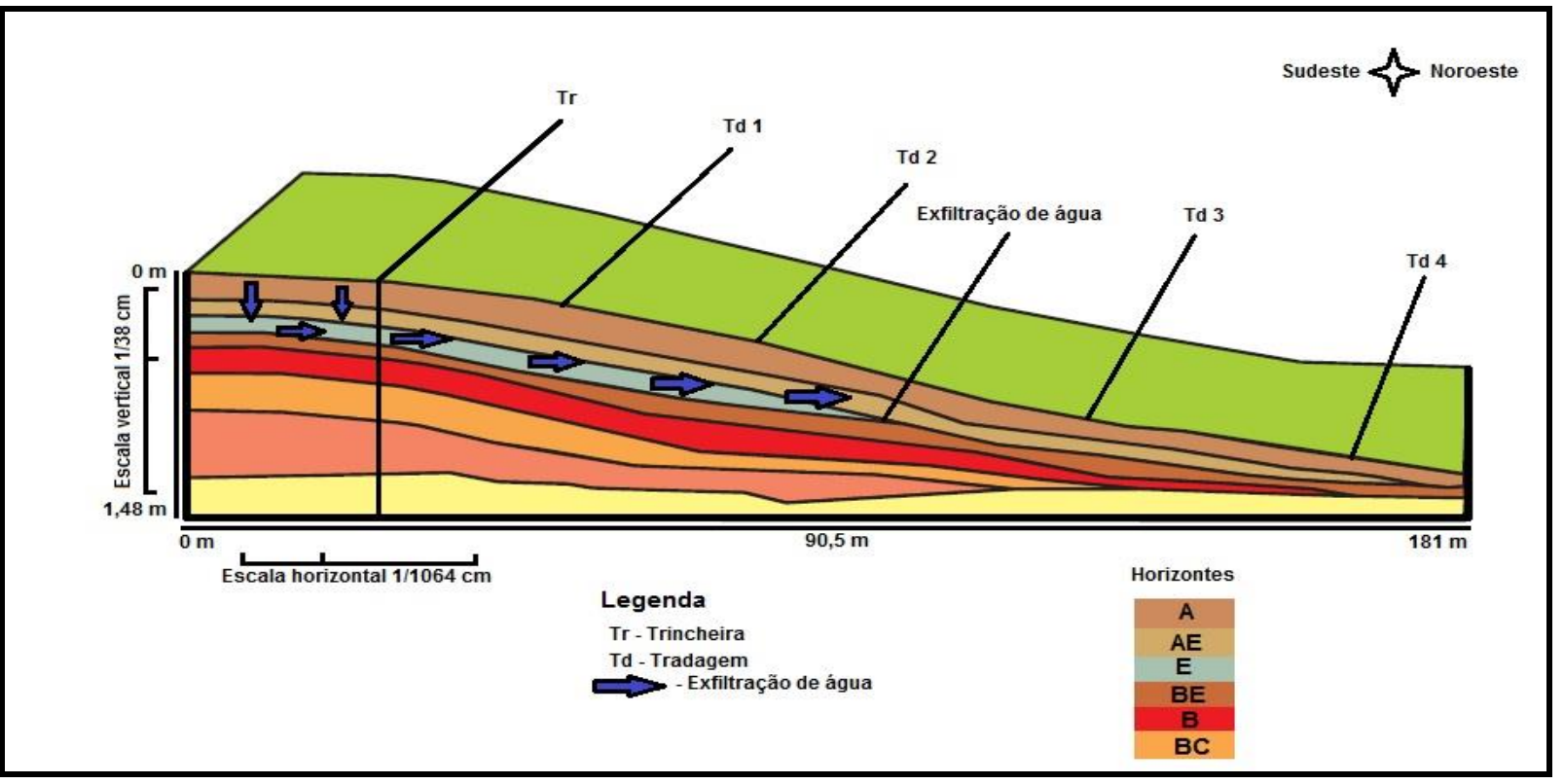

Fonte: Organização dos autores

Observa-se que os horizontes subsuperficiais, controlam o fluxo lateral de água. Portanto, as características físico-hídricas influenciam no perfil convexo-côncavo dessa vertente. 
Após a análise dos resultados obtidos para o tamanho de partículas e os parâmetros físico-hídricos dos horizontes diagnósticos das cinco vertentes modais, selecionadas sobre o substrato litológico da Formação Santa Maria (Membro Alemoa), assevera-se que, apesar das vertentes situarem-se sobre o mesmo substrato litológico e estarem sujeitas ao mesmo clima e ao mesmo tempo de evolução, cada vertente exibiu suas particularidades, devido a microambientes de evolução. Entretanto, é possível comprovar que existe, na dinâmica evolutiva da forma do perfil das vertentes estudadas, influência dos parâmetros físico-hídricos dos horizontes diagnósticos do solo. Essa influência se manifesta na vertente após o processo de formação do solo, onde os horizontes adquirem características que os fazem interferir na dinâmica da vertente. Corroborando com isso está a afirmação de Toledo et al. (2008), que conclui que os solos primeiramente se formam e depois passam por processos de mudança.

As vertentes em estudo apresentaram características semelhantes, entre elas, a forma do perfil convexo-côncavo. Em relação aos processos pedogenéticos, pode-se inferir que, em comum às vertentes em estudo, está a translocação de argila dos horizontes diagnósticos superficiais para os horizontes diagnósticos subsuperficiais (podzolização).

Esse mecanismo contribui para a formação de horizontes argilosos, com horizonte B textural menos impermeáveis, acarretando na formação de fluxos laterais de água em subsuperfície. Também se constatou ser comum entre as vertentes a presença de cascalhos formados por concreções ferruginosas. Em alguns casos, a presença dessas concreções formam horizontes concrecionários. Ao se situarem no terço superior da vertente, eles contribuem para a manutenção do segmento convexo presente nelas. 


\section{CONCLUSÃO}

Conclui-se, pois, que essas vertentes estão em evolução e a morfogênese atual experimenta a influência das propriedades físico-hídricas do manto pedológico. $\mathrm{O}$ escoamento superficial e os fluxos hídricos em subsuperfície promovem a morfogênese e atribuem o predomínio de perfis com a forma convexa no terço superior e côncava no terço médio e inferior das vertentes estudadas, formando o perfil convexo-côncavo, frequentemente observado na área de estudo. Portanto, infere-se que as propriedades físico-hídricas do solo influenciam a conformação do perfil convexo-côncavo das vertentes pesquisadas.

\section{REFERÊNCIAS}

AYOADE, J. O. Introdução à Climatologia para os Trópicos. São Paulo: Difel,1986.

BERTALANFFY, L. V. Teoria dos sistemas. Rio de Janeiro: Fundação Getúlio Vargas, 1976.

BIGARELLA, J. J.; MOUSINHO, M. R.; XAVIER DA SILVA, J. Considerações a respeito da evolução das vertentes. Boletim Paranaense de Geografia, v. 16 e 17, p. 85-116, 1965.

BORTOLUZZI,C.A. Contribuição à Geologia da Região de Santa Maria, Rio Grande do Sul, Brasil, 1974.

BOULET R. Existence de systèmes à forte différentiation laterale em milieu ferralitique guyanais: un nouvel exemple de couverture pédologique en déséquilibre. Science du Sol, 1978.

BOULET R.. et al. Analyse structurale et pédologie. I. - Prise en compte de l'organisation bidimennelle de la couverture pédologique: les études de toposéquences et leurs principaux apports à la connaissance des sols. ORSTOM, Série Pédol., v. 19., p. 309-322, 1982a.

BOULET R. HUBEL, F. X; LUCAS, Y. Analyse structurale et cartographie em pédologie. II - Une méthode d'analyse prennant en compte l'organisation tridimensionelle des couvertures pédologiques. ORSTOM, Série Pédol., v. 19., p. 323-339, $1982 b$. 
BOULET R. Análise estrutural da cobertura pedológica e cartografia. In: CONGRESSO BRASILEIRO DE CIÊNCIA DO SOLO, 25., Campinas, 1988. Anais. Campinas: Sociedade Brasileira de Ciência do Solo, 1988.

BOULET R. Uma evolução recente da Pedologia e suas implicações no conhecimento da gênese do relevo. In: CONGRESSO ABEQUA, 3., Belo Horizonte, 1992. Anais. Belo Horizonte, 1992.

CHRISTOFOLETTI, A. Geomorfologia. São Paulo: Edgard Blücher, 1980.

CRUZ, O. Estudo dos processos geomorfológicos do escoamento pluvial na área de Caraguatatuba/São Paulo. Tese (Livre Docência)-FFLCH-USP, São Paulo, 1982.

GREGORY, K. J. A natureza da geografia física. São Paulo: Bertrand Brasil, 1992.

LAKATOS, E. M.; MARCONI, M. de A.. Fundamentos de metodologia científica. 4. ed. rev. e ampl. São Paulo: Atlas, 2001.

PELLERIN, J.; QUEIROZ NETO, J. P. Morfogênese e pedogênese no córrego da invernada (Marilia, SP). In: CONGRESSO ABEQUA, 32., 1992. Anais... Belo Horizonte, 1992a. p. 111-120.

PELLERIN, J.; QUEIROZ NETO, J. P.. Relations entre la distribution des sols, les formes de relief et I'évolution géomorphologique du relief dans la haute vallée du rio do peixe (état de S. Paulo, Brésil). Sci. Du Sol, Paris, v. 30, a. 3, p. 133-147, 1992b.

QUEIROZ NETO, J. P. Análise estrutural da cobertura pedológica no Brasil. In: CONGRESSO BRASILEIRO DE CIÊNCIA DO SOLO, 21., 1988. Campinas. Anais... Campinas, 1988.

QUEIROZ NETO, J. P. Análise Estrutural da Cobertura Pedológica: Uma Experiência de Ensino e pesquisa. Revista do Departamento de Geografia, 2002.

QUEIROZ NETO, J. P. Geomorfologia e pedologia. Revista Brasileira de Geomorfologia, v. 1, n. 1, 2010.

ROSS, J. L. Geografia do Brasil. São Paulo: Edusp, 1996.

RUELLAN, A.; DOSSO, M.; FRITSH, E. L'analyse structurale de la couverture pédologique. Sciences of Soils, v. 27, p. 319-334, 1984. 
SARTORI, M. da G. B. A dinâmica do clima do RS: Indução empírica e conhecimento científico. Revista Terra Livre, São Paulo, a 19, v. 1, n. 20, 2003.

SARTORI, P. L. Geologia e geomorfologia de Santa Maria. Ciência e Natura, n. 38, 2009.

TOLEDO, M. C. M.; OLIVEIRA, S. M.; MELFI, A. J. Intemperismo e formação do solo. In: TEIXEIRA, W.; TOLEDO, M. C. M.; FAIRCHILD, T. R.; TAIOLI, F. Decifrando a Terra. São Paulo: Companhia Editora Nacional, 2008.

TRICART, J. Le modele des regions chaudes, forets et savanes. Paris: SEDES, 1965.

VIEIRA, E. F. Rio Grande do Sul. Geografia física e vegetação. Porto Alegre: Sagra, 1984. 